\title{
Spatial and Temporal Quantification of the Morphofunctional Components of the Zebrafish kidneys
}

\author{
Anna clarasantos ${ }^{1}$, Kaique Nogueira ${ }^{1}$,Cecília Ferreira Amaral Silva ${ }^{1}$,Paulo Henrique de Sampaio da \\ Silva ${ }^{1}$,André Rodrigues da Cunha BarretoVianna ${ }^{2 *}$ andEduardo Maurício Mendes de Lima ${ }^{1}$ \\ ${ }^{1}$ Faculty of Agronomy and Veterinary Medicine, University of Brasília (UnB), Federal District, Brazil \\ ${ }^{2}$ Department of Veterinary Medicine, Federal University of Lavras (UFLA), Brazil
}

Submission: May 23, 2018; Published: July 02, 2018

*Corresponding author: Eduardo Maurício Mendes de Lima, Faculdade de Agronomia e Medicina Veterinária, Universidade de Brasília (UnB), Distrito Federal, Brazil. Email: limaemm@unb.br

\begin{abstract}
Zebrafish is a small fish of the teleost family that has been widely used in animal experimentation to replace the use of rodents. It is characterized as a well defined study model capable of providing experimental information in several research areas. The present work aimed to analyze the spatiotemporal alterations of Zebrafish's kidney architecture through the measurement of glomerular volume and stromal cell volume over thirteen weeks. We used 72 fish of the species Danio rerio, 6 months old, divided into thirteen groups, so that each group constituted one week. At the end of each week the euthanasia of the animals was promoted and the animals were fixed in aqueous solution of $10 \%$ formaldehyde, followed by conventional histological technique, cuts of $4 \mu \mathrm{m}$ thickness and subsequent staining with Hematoxylin-Eosin. Photomicrographs of 3 random fields of each fragment were obtained, being three fragments per animal and three animals per week. The quantification of the occupied area (volume density) was done through the point analysis, and the data were submitted to descriptive statistical analysis, Kolmogorov-Smirnov normality test, one-way ANOVA variance analysis with Holm-Sidak post test, in addition to the Pearson correlation test. P $\leq 0.05$ was considered significant. No statistical difference was observed in the volume density of the renal stroma between the analyzed weeks $(P>0.05)$. Likewise, no statistical difference was observed between weeks in the volume density of the glomeruli $(\mathrm{P}>0.05)$. By correlating the passage of weeks with the volume densities of the structures evaluated, there was no statistical significance, nor was there any significant correlation between the volume densities of the stroma and the glomerulus. In the present study, during the 13 weeks analyzed, we did not find significant morphological and structural differences in relation to the volume density of the stroma and in relation to the glomerular volume density of the Zebrafish kidneys analyzed.
\end{abstract}

Keywords: Glomerular volume;Renal morphology;Stromal cells; Diseases; Organic functions; Hematopoiesis; Zebrafish; Animal; Stroma; Glomeruli; Nephrons; Aqueous solution; Photomicrographs; Carbon; Densities

\section{Introduction}

Zebrafish has become a well-established study model, contributing to the identification and characterization of developmental genes, various organic functions, behavior and diseases [1]. This small fish also emerged as a vertebrate that can easily be genetically modified and is often used for renal biology studies associated with the medical conditions related to this system in both the embryo and adult situations [2].The kidneys are composed of nephrons, functional units of the organ, composed of a configuration of specialized tubular epithelium divided into glomeruli, whose function is to filter the blood; proximal and distal tubules, secreting and / or reabsorbing specific molecules; and the collecting duct [3]. The Zebrafish's kidney is found in the retroperitoneal region, ventral to the spine
[4] and plays an important role in hematopoiesis, since the bones of this animal do not have marrow cavity [5].

From these aspects, we aimed to analyze the spatiotemporal alterations of the Zebrafish kidney architecture, such as glomerular volume and renal stromal volume. For this purpose, morphometric and stereometric evaluations of the Zebrafish kidney of different ages were evaluated in a comparative way, aiming in particular to support future studies on this organ and the species in question.

\section{Materialand Methods}

This study was approved by the Committee of Ethics in Animal Experimentation of the University of Brasilia under 
protocol no. 127542/2013.Were used seventy-two adults Danio rerio fish, aged 6 months, of both sexes, underwent a 10-day acclimatization period in a $30 \mathrm{~L}$ aquarium, maintaining the appropriate population density to avoid population stress, were later divided into thirteen groups that were kept in different and identified aquaria, each group corresponding to one week of experiment, totaling 13 weeks. All the aquariums were acclimatized with a constant temperature of $24 \pm 2^{\circ} \mathrm{C}$ controlled by a thermostat and $\mathrm{pH}=6.8-7.0$ daily verified with the aid of the Tropical pH kit (LabconTest) and corrected, when necessary, with Alcali (Labcon $®)$. Maintenance was carried out through mechanical filters (Motorized Submersible Pump SB 160V, Sarlo®Better), biological and chemical (activated carbon).At the end of each week euthanasia was promoted by immersing the fish in aqueous solution of tricaine $0.2 \%$ methanesulfonate and $\mathrm{pH}=7.0$ (Finquel MS-222 $($, Argent Laboratories Group $®$ ), followed by immersion in ice water $\left(4^{\circ} \mathrm{C}\right)$ for 15 minutes [6].

The fish were fixed in $10 \%$ aqueous solution of formaldehyde for 24 hours, then submitted to the conventional histological technique. Subsequently, with the use of the hand microtome (Leica RM 2125RT), they were cut in a thickness of $4 \mu \mathrm{m}$, packed in blades and stained with Hematoxylin and Eosin for visualization of renal tissue.Photomicrographs of three random fields from each fragment, three fragments from each animal and three animals per week, were obtained with the help of the optical microscope (BX51 Olympus $®$ ) coupled to the program of image capture and analysis (ProgRes $®$ Capture Pro 2.5) . Quantification of the volume density (Vv) of the glomeruli (Vv [glomeruli]) and of the stroma ( $\mathrm{Vv}$ [stroma]) was performed using STEPanizer ${ }^{\circledR}$ stereology software (http://stepanizer.com/).Data were acquired and analyzed using the GraphPad Prism® program6. Descriptive statistics were initially performed, followed by the Kolmogorov-Smirnov normality test, one-way ANOVA and posttest of Holm-Sidak or Friedmann, according to the normality test. It was considered statistically significant when $\mathrm{p} \leq 0.05$.

\section{Results}

The volume density of the renal stroma ( $\mathrm{Vv}$ [stroma]) during the 13 weeks evaluated showed a normal distribution. The lowest Vc (stroma) occurred in the 11 thweek $(27.78 \% \pm 3.07)$, while the highest occurred in the 10 th week $(46.3 \% \pm 4.85)$ (Figures 1 and 2 ). However, we did not observe statistical difference in the volume density of the renal stroma between weeks ( $\mathrm{p} \leq 0.05)$.Regarding the glomerular volume density (Vv [glomerulus]), it also had a normal distribution throughout all evaluated weeks. The lowest and highest values of $\mathrm{Vv}$ (glomeruli) occurred, respectively, in the first week $(1.85 \% \pm 0.92)$ and in the 8 th week $(5.58 \% \pm 2.02)$ (Figures 1). However, we did not observe statistical difference in the density of glomerular volume between weeks $(\mathrm{p} \leq 0.05)$. When the Pearson test correlated the weeks with the stromal and glomerulus volume densities, it was found that there was no statistical significance for both the stromal volume density and the volume density of the glomeruli(Figure 2).

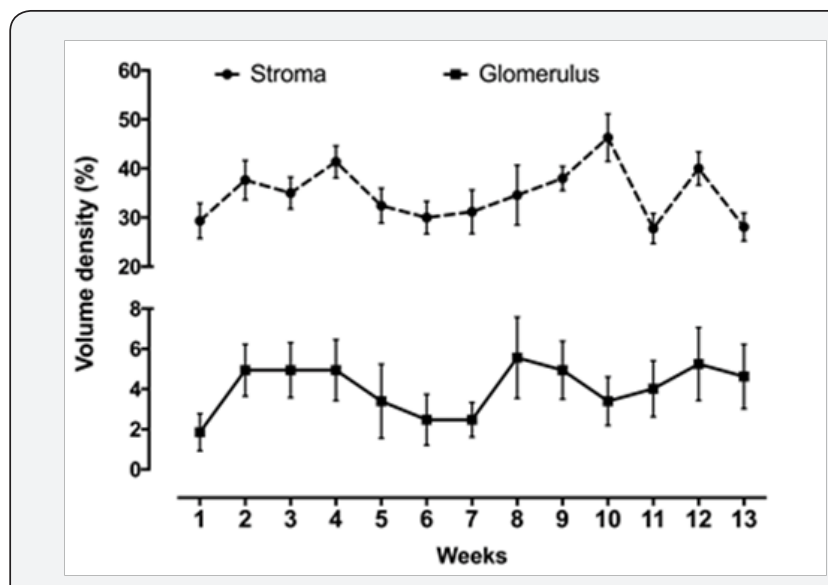

Figure 1: Representative graphs expressing mean values and standard error of mean stromal volume density (dashed line) and volume density of glomeruli (solid line) of Zebrafish kidneys over 13 weeks.

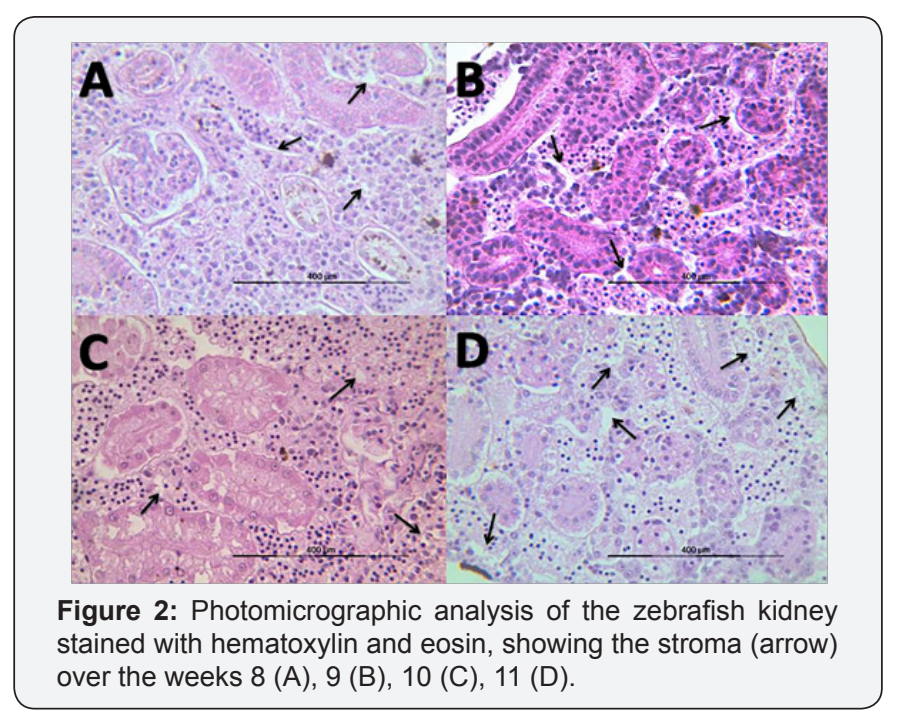

\section{Discussion}

The description of the renal components of adult individuals is an important tool to support studies related to kidney alterations in senile individuals [7,8].It was not possible to observe a quantitative increase or diminution of the Zebrafish renal components during the 13 weeks. Despite this, embryos of this fish with 14 days post fertilization showed continuously developing nephrons, demonstrated by the increase in the number of this structure in the kidneys until the adult phase. Thus, it is believed that up to a certain age the Zebrafish kidneys have an upward developmental curve and, when they reach adulthood, there is a plateau, where the renal structures remain somewhat unchanged. This curve is likely to decrease when reaching senile age, which was not verified during the analyzed 13 weeks, where the animals reached about 37 weeks of age.

Zebrafish has very rapid development, thus, glomerular filtration, even if immature and not completely efficient, begins around 48 hours after fertilization. The complete maturation with the perfect selective filtering capacity occurs 96 hours after 
fertilization, where the complete development of the podocytes and glomerular fenestrations is already verified [9]. Although the renal development occurs at very early stages, the neonephrosis process, that is, the formation of new nephrons occurs throughout the life of the zebrafish, where there is a positive correlation between the addition of new nephrons and body mass of these fish[10-14].The neonephrosis observed throughout the life of the fish may be related to the high capacity of regeneration of the damaged nephrons[15-22]. The findings of the present study corroborate this high plasticity of renal constituents in the adult phase of zebrafish, where we found no quantitative difference in renal components over the weeks. Thus, fish appear to exhibit this protective aspect, keeping the renal elements in relatively stable quantity throughout their life, or at least throughout the adult phase, as verified in this study.

\section{Conclusion}

In the present study, during the 13 weeks analyzed, it was not possible to evaluate significant morphological and structural differences regarding the glomerular volume and the stroma of the Zebrafish kidneys analyzed, since they remained constant in their results and did not present statistical significance when compared. In order to know the morphological behavior of the Zebrafish kidney in senile animals, we believe that it would be interesting to carry out new studies, increasing the evaluation interval.

\section{References}

1. Sprague J, Bayraktaroglu L, Clements D, Conlin T, Fashena D et al. (2006) The Zebrafish Information Network: the zebrafish model organism database. Nucleic acids research 34(1): D581-D585.

2. McCampbell KK, Wingert RA (2014) New tides: using zebrafish to study renal regeneration. Translational Research 163(2): 109-122.

3. Reilly RF, Bulger RE, Kriz W (2007) Structural-functional relationships in the kidney. Diseases of the Kidney and Urinary Tract, 1: 2-53.

4. Menke AL, Spitsbergen JM, Wolterbeek APM, Woutersen RA (2011) Normal Anatomy and Histology of the Adult Zebrafish. Toxicologic Pathology 39: 759-775.

5. Ellett F, Lieschke GJ (2010) Zebrafish as a model for vertebrate hematopoiesis. Current opinion in pharmacology, 10(5): 563-570.

6. Gupta T, Mullins MC (2010) Dissection of organs from the adult zebrafish. JoVE (Journal of Visualized Experiments) 37: 1717.
7. Sampaio KMO, Araújo RB (2002) Ultra-sonografia de características lineares e estimativas do volume de rins de cäes. Arq. Bras. Med. Vet. Zootec, 54(3): 248-254.

8. Lustoza MD, Kogika MM (2003) Tratamento de insuficiência renal crônica em cães e gatos. Medina Veterinária Revista Brasileira de Medicina Veterinária. Curitiba, 1(1): 62-69.

9. Kramer Zucker AG, Wiessner S, Jensen AM, Drummond IA (2005) Organization of the pronephric filtration apparatus in zebrafish requires Nephrin, Podocin and the FERM domain protein Mosaic eyes. Developmental Biology, 285(2): 316-329.

10. Diep CQ, Peng Z, Ukah TK, Kelly PM, Daigle RV etal. (2011) Development of the zebrafish mesonephros. Genesis 53(3e4): 257e269.

11. Diep CQ, Peng Z, Ukah, TK, Kelly PM, Daigle RV et al. (2015) Development of the zebrafish mesonephros. Genesis, 53(3,4): 257-269.

12. Zhou W, Boucher RC, Bollig F, Englert C, Hildebrandt F (2010) Characterization of mesonephric development and regeneration using transgenic zebrafish. American Journal of Physiology 299(5): F1040-F1047.

13. Zhou W, Boucher RC, Bollig F, Englert C, Hildebrandt F (2010) Characterization of mesonephric development and regeneration using transgenic zebrafish. Am J Physiol Renal Physiol 299: F1040-F1047.

14. Drummond IA, Davidson AJ (2016) Chapter 12 - Zebrafish kidney development. Methods in biology cell 134: 391-429.

15. Reimschuessel RA (2001) Fish model of renal regeneration and development ILAR J 42: 285-291.

16. Ablain J, Zon LI (2013) Of fish and men: using zebrafish to fight human diseases. Trends in cell biology 23(12): 584-586.

17. Agopian RG, Guimarães KP, Fernandes RA, Vinícius M, Silva M et al. (2016) Estudo morfométrico de rins em felinos domésticos (Felis catus). Pesq Vet Bras 36(4): 329-338.

18. Barros TP, Alderton WK, Reynolds HM, Roach AG, Berghmans S (2008) Zebrafish: an emerging technology for in vivo pharmacological assessment to identify potential safety liabilities in early drug discovery.British journal of pharmacology, 154(7): 1400-1413.

19. DiBartola SP, Rutgers HC, Zack PM, Tarr MJ (1987) Clinicopathologic findings associated with chronic renal disease in cats: 74 cases. Journal of the American Veterinary Medical Association,190(9): 1196-1202.

20. Elliott J, Barber PJ (1998) Feline chronic renal failure: clinical findings in 80 cases diagnosed between 1992 and 1995. Journal of Small Animal Practice, 39(2): 78-85.

21. Kinth P, Mahesh G, Panwar Y (2013) Mapping of zebrafish research: a global outlook. Zebrafish, 10(4): 510-517.

22. Menke AL, Spitsbergen JM, Wolterbeek APM, Woutersen RA (2011) Normal Anatomy and Histology of the Adult Zebrafish. Toxicologic Pathology, 39: 759-775. 


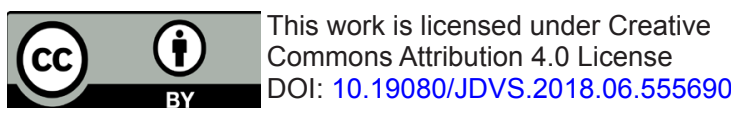

- Swift Peer Review

- Reprints availability

- E-prints Service

- Manuscript Podcast for convenient understanding

- Global attainment for your research

- Manuscript accessibility in different formats

( Pdf, E-pub, Full Text, Audio)

- Unceasing customer service

Track the below URL for one-step submission https://juniperpublishers.com/online-submission.php 